\title{
EXPERIMENTAL AND THEORETICAL STUDIES OF FRICTION AND HEAT TRANSFER IN ROUGH PASSAGES
}

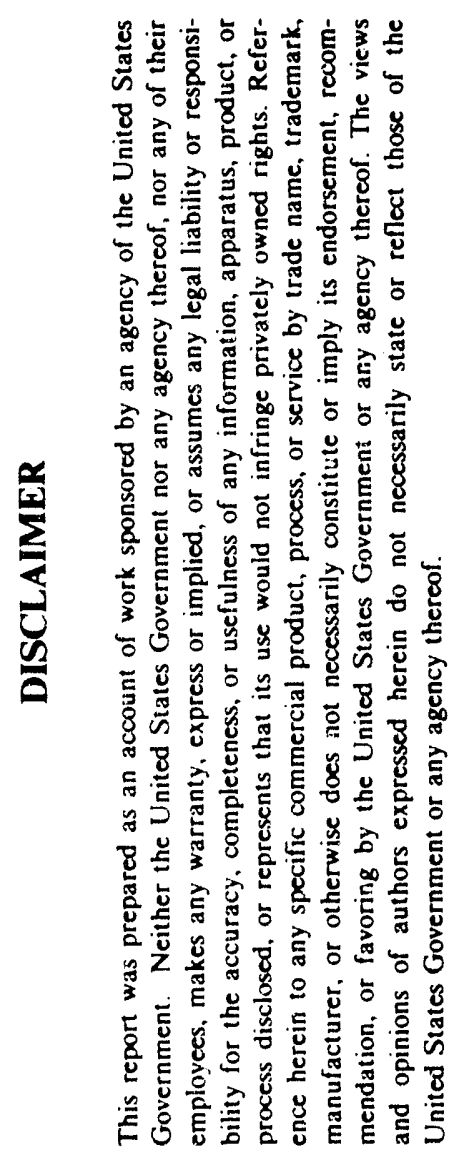

\author{
Progress Report \\ for Period August 1, 1990 - November 30, 1990 \\ N. T. Oboi and E. B. Esen \\ $>$ \\ Clarkson University \\ Potsdam, New York 13699
}

December 1990

Prepared for

THE U. S. DEPARTMENT OF ENERGY

AGREEMENT NO. DE-FG02-89CE90029.A000 


\section{Experimental and Theoretical Studies of Friction and Heat Transfer in Rough Passages}

\section{INTRODUCTION.}

A paper based on the results presented in the first final report (DOE/CE/90029-2) and entitled "The Role of Transition in Determining Friction and Heat Transfer in Smooth and Rough Passages" was published in the October issue (Volume 33) of the International Journal of Heat and Mass Transfer. A reprint of the article is appended to this report. Within this short period, many reprint requests (from this country, England, Israel and Canada) have been received. We have also received requests for the original report (DOE/CE/90029-2).

\section{RECENT PROGRESS}

Beginning with the minimum objectives established at the outset of the period covered by this report, the general picture can be summed up as follows: detailed heat transfer and pressure drop (with and without heating) measurements with the smooth tube, fabrication of the eleven (enhanced tube) heat transfer test sections, tests with two of the three Hitachi tubes, and che construction of the liquid test facility were completed. In short, the minimum objectives were, for the most part, accomplished satisfactorily.

\subsection{Smooth Tube Friction and Heat Transfer Results.}

The extensive air tests with the smooth tube served two objectives; first, the results provided validation of the instrumentation as well as the data reduction procedures; and second, the tests were crucial in the determination of the procedures adopted for subsequent tests with the enhanced tubes. A summary of the test conditions for the smooth tube is given in Table 1.

\section{Constant Average Surface Temperature.}

For these tests, the average surface temperature was held fixed (Table 1) with increasing Reynolds number between 700 and 50000 . The real advantage of this approach is that the bulk temperature rise, i.e., the difference between the exit and inlet air temperatures, is roughly constant for all Reynolds numbers $(R e)$. Hence, the physi,al properties of air, used 
in the computation of Nusselt number $(N u)$ and $R e$, are almost independent of the Reynolds number, whether these are evaluated using the average of inlet and exit temperatures or the film temperature. Also, given the near constancy of the physical properties over the entire Re range, this approach affords accurate determination of the role of heat transfer on transition. The disadvantage, however, is that, due to the painstaking, fine-tuning of the power input to obtain the desired average surface temperature, the duration of a test is considerably longer than for the constant heat flux mode to be discussed subsequently.

Table 1. Summary of test conditions for smooth tube.

\begin{tabular}{c|c}
$\begin{array}{c}\text { Bulk Temperature Rise } \\
\text { (laminar-turbulent), }{ }^{\circ} \mathrm{C}\end{array}$ & $\begin{array}{c}\text { Average Surface Temperature Range } \\
\text { (laminar-turbulent), }{ }^{\circ} \mathrm{C}\end{array}$ \\
\hline 10 & 53 (constant surface temperature) \\
\hline $22-5$ & $75-42\left(q=773 \mathrm{~W} / \mathrm{m}^{2}\right)$ \\
$44-5$ & $131-41\left(q=1708 \mathrm{~W} / \mathrm{m}^{2}\right)$ \\
$59-4$ & $158-59\left(q=2509 \mathrm{~W} / \mathrm{m}^{2}\right)$ \\
\hline \hline
\end{tabular}

Figures 1 and 2 respectively are plots of Nusselt number $(N u)$ and friction factor $(f)$ versus Reynolds number, while comparison of the present heat transfer data with the air data of Ravigururajan and Bergles (1986) is given in Figure 3. Clearly, the heat transfer profile consists basically of three regions: laminar flow trend which is characterized by moderate increase with $R e$, a transition region with a rise in heat transfer, and a turbulent heat transfer zone which begins right after the transition region. The presence of three well-defined heat transfer zones is consistent with the friction factor trend.

Also, the shape of the heat transfer profile of Figure 1, beginning from laminar flow to the end of the transition region, is remarkably similar to those reported by Kaupas et al. (1989) and is more well defined than that of Nunner (1956) or Koch (1960). The agreement with the data of Ravigururajan and Bergles is good, as is the case with the Petukhov-Popov (1963) correlation. 


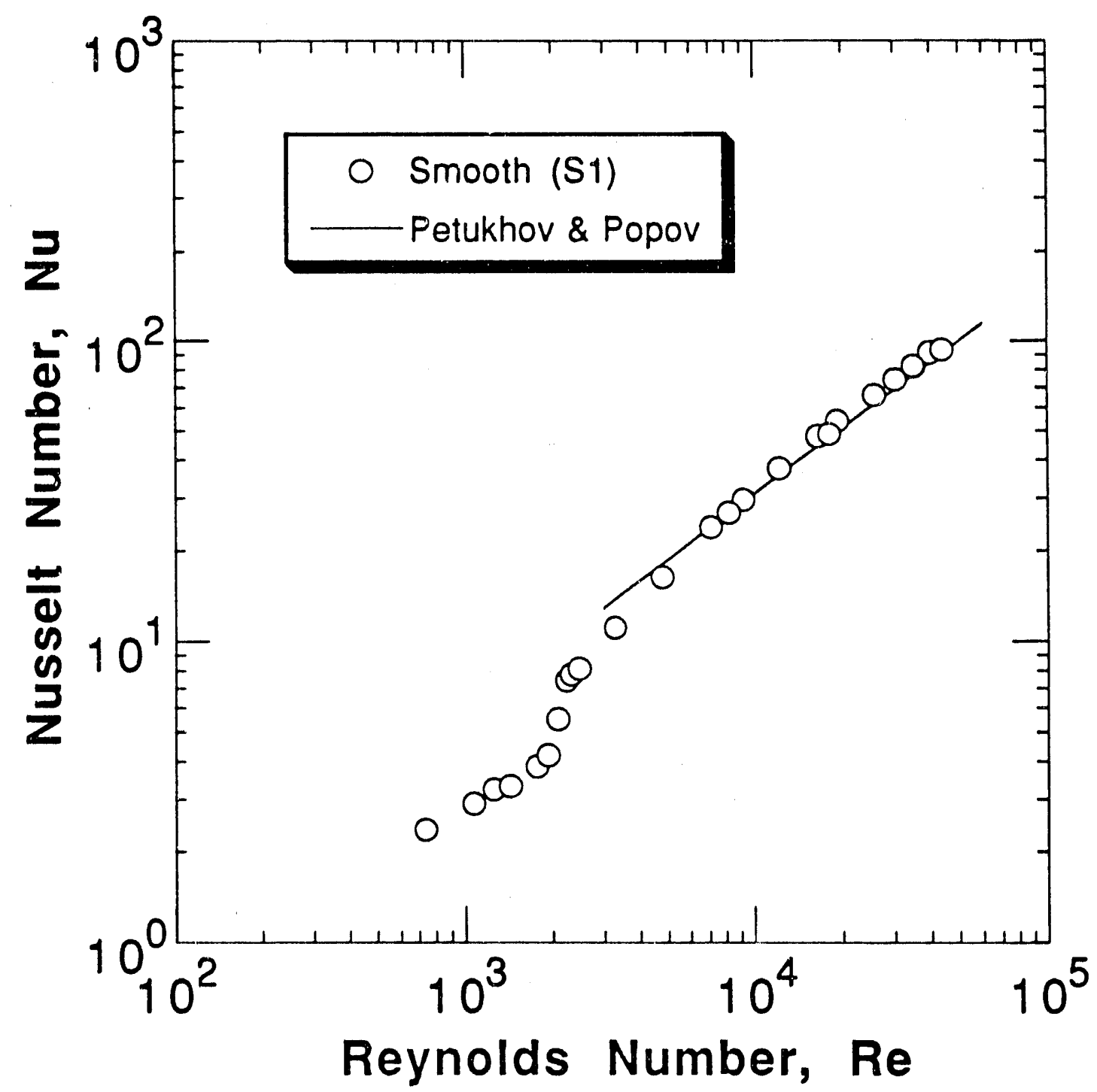

Figure 1. Nu vs. Re for constant average surface temperature. 


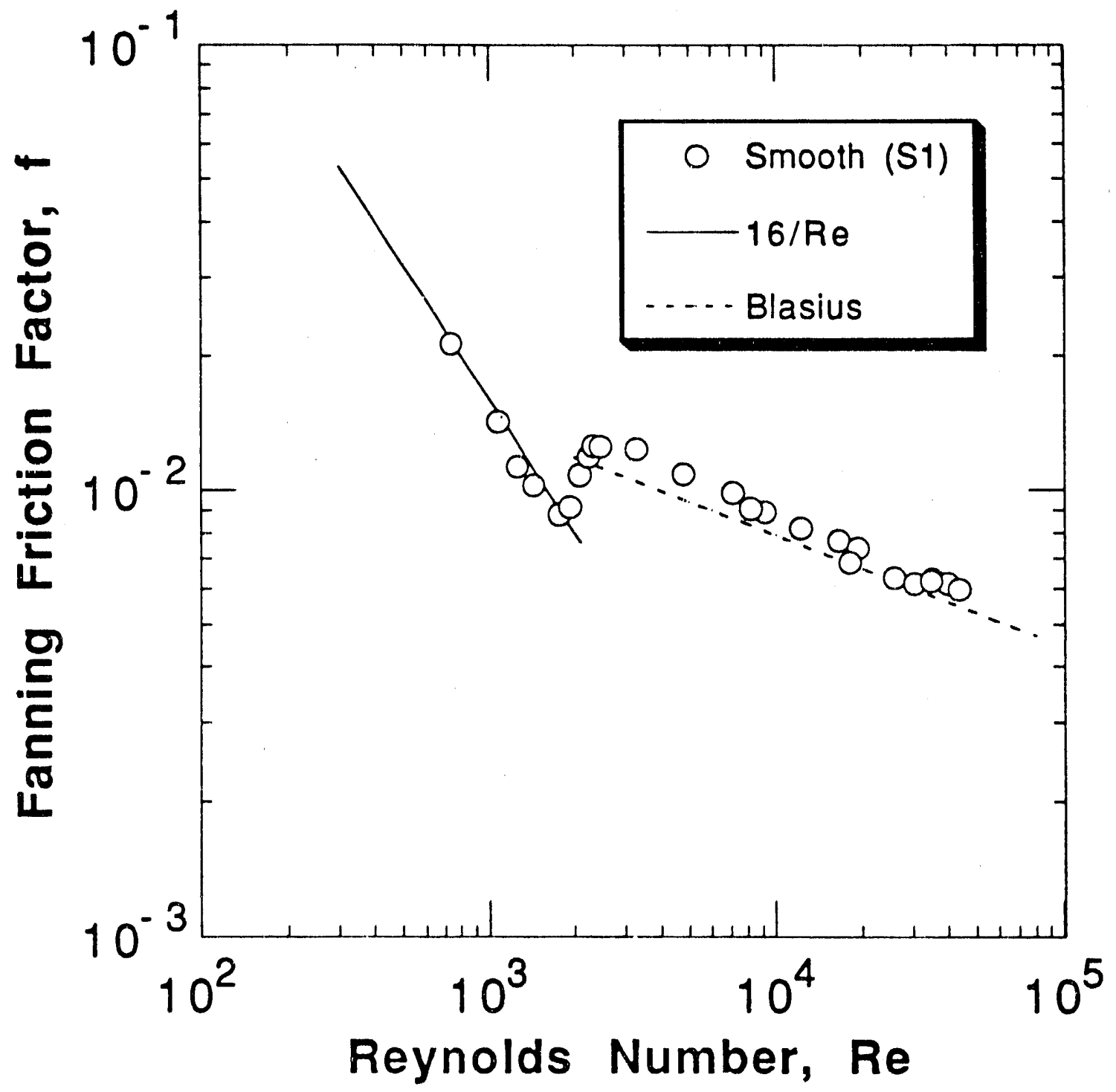

Figure 2. $f$ vs. Re for constant average surface temperature. 


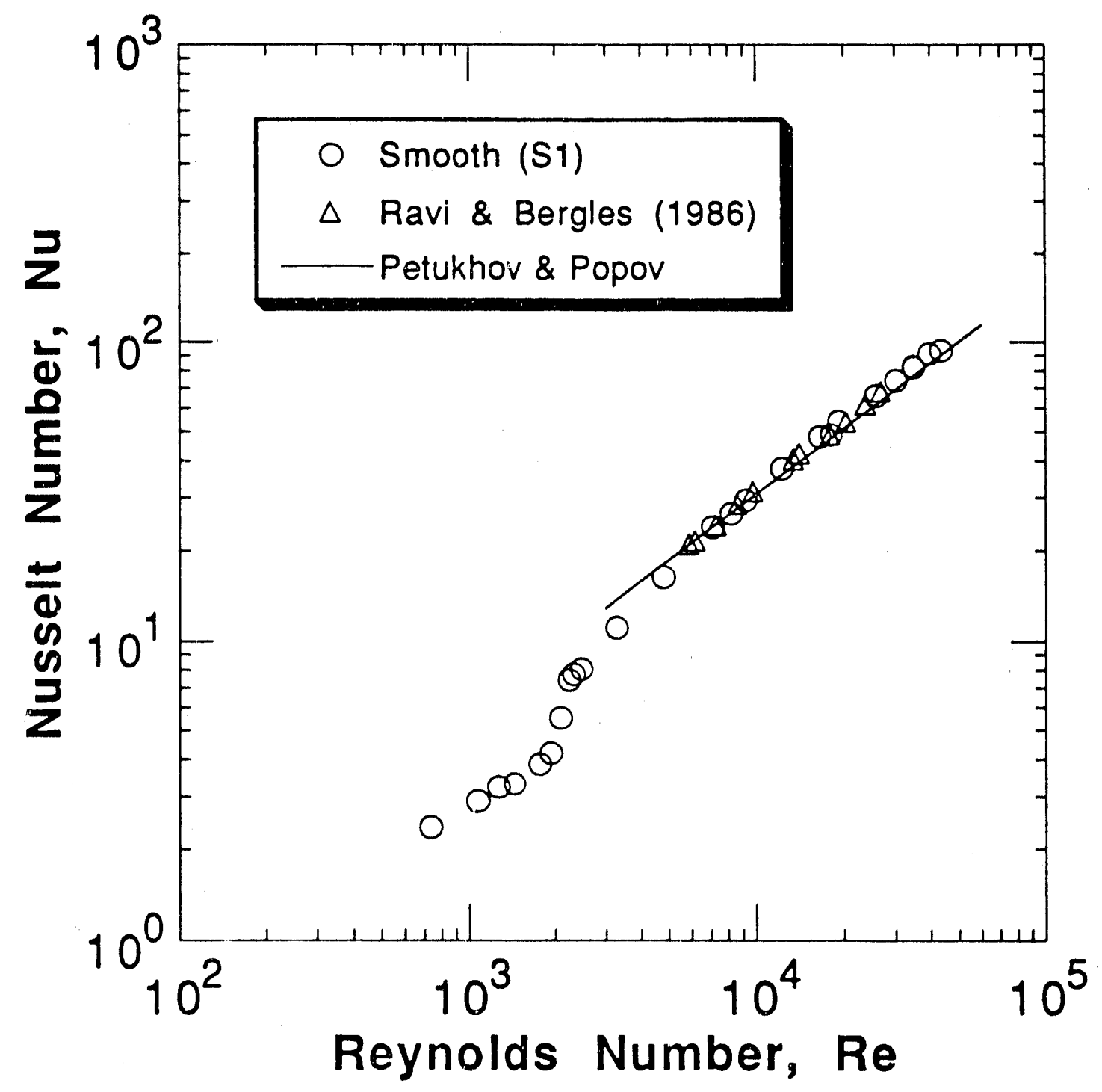

Figure 3. Comparison of present data with previous results. 


\section{Constant Heat Flux.}

Tests were carried out with three values of heat flux (Table 1). The maximum attainable Reynolds number for each flux was determined by the requirement that the air temperature rise at the exit of the test section be no less than $5^{\circ} \mathrm{C}$. Thus the Reynolds number range for the results of Figures 4 and 5 increases with increasing heat flux. For the sake of clarity, and in order to consolidate the heat iransfer or friction results into a single figure, the data for $q=$ 1708 and $2509 \mathrm{~W} / \mathrm{m}^{2}$ are scaled by factors of 2 and 4 , respectively.

With regard to the influence of heat flux, it is easily established from inspection of Figure 4 or 5 that the critical Reynolds number at the onset of iransition decreases with increasing q. Consequently, the average Nusselt numbers in laminar flow and in the transition zone also increase with $q$, regardless of whether the physical properties are evaluated using the average of the inlet and exit air temperatures, as is the case for the results presented herein, or using the film temperature. Infact, these residual effects of heat flux are still in evidence in the turbulent regime. This is easily established by noting the locations of the daia points relative to the Petukhov-Popov correlation (solid lines).

From comparison between Figures 2 and 5 it is evident that the constant heat flux gives inconsistent friction factor variations with increasing Reynolds number due, of course, to the temperature effect. In laminar flow and for $1900<R e<5000$, the values are significantly higher than those without heating except, of course, at the lowest flux level; but the two sets of data are roughly about the same for $R e>5000$.

To shed further light on the effect of heat flux on friction factor, especially since previous researchers rarely reported data with heating or cooling even for the most widely studied turbulent flow regime, a plot of $\Delta p_{w h} / \Delta p_{w}\left(\Delta p_{w h}\right.$ and $\Delta p_{w}=$ pressure with and without heating, respectively) as a function of the Reynolds number is given in Figure 6. Note that the scaling factor, $\Delta p_{w}$, is the steady state pressure drop recorded at each flow Reynolds number just before the onset of heating of the test section. The characteristic feature of each profile is the presence of a maximum in the vicinity of the Reynolds number at which transition to turbulence begins, 


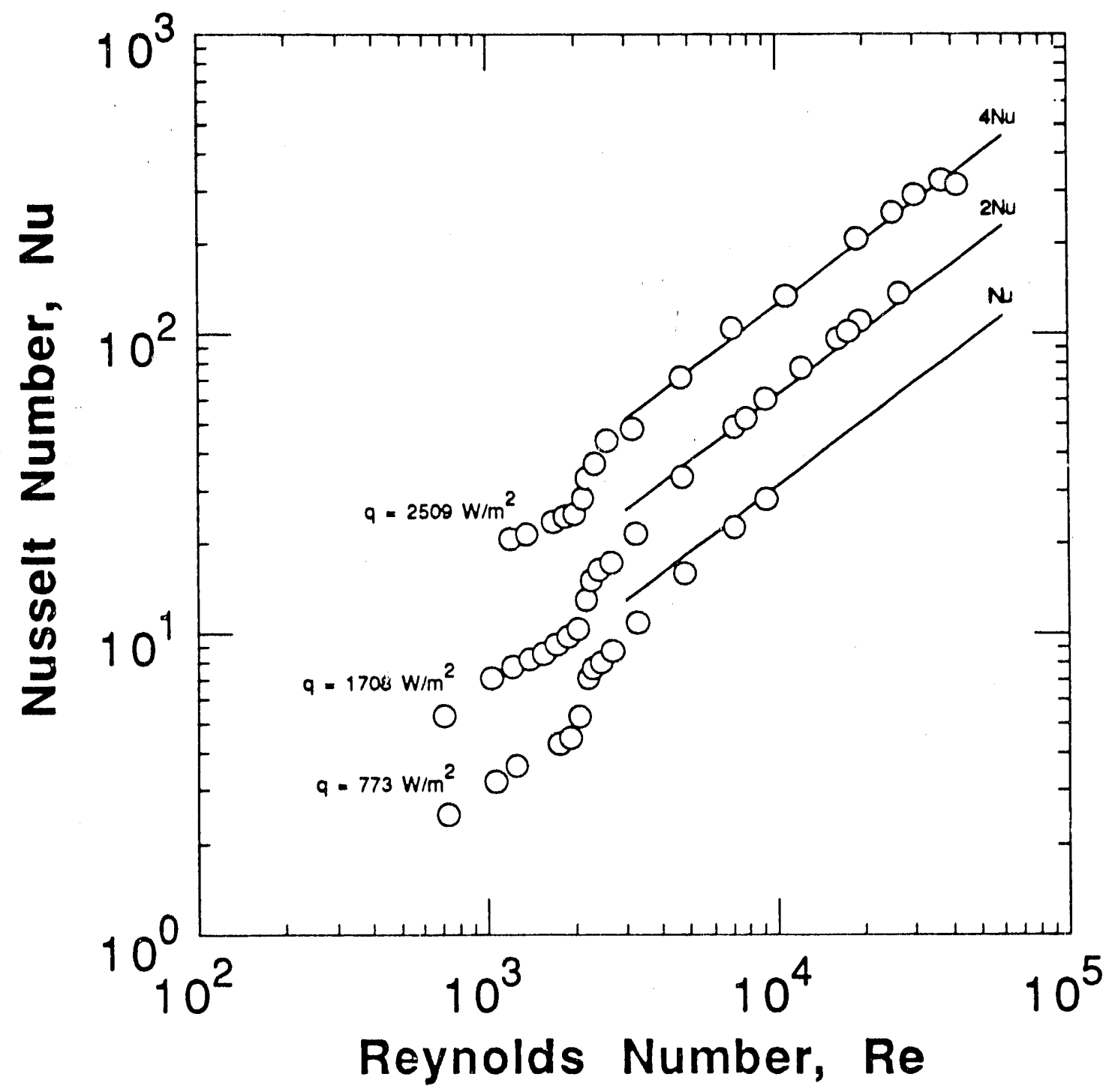

Figure 4. Nu vs. Re for three values of heat flux. 


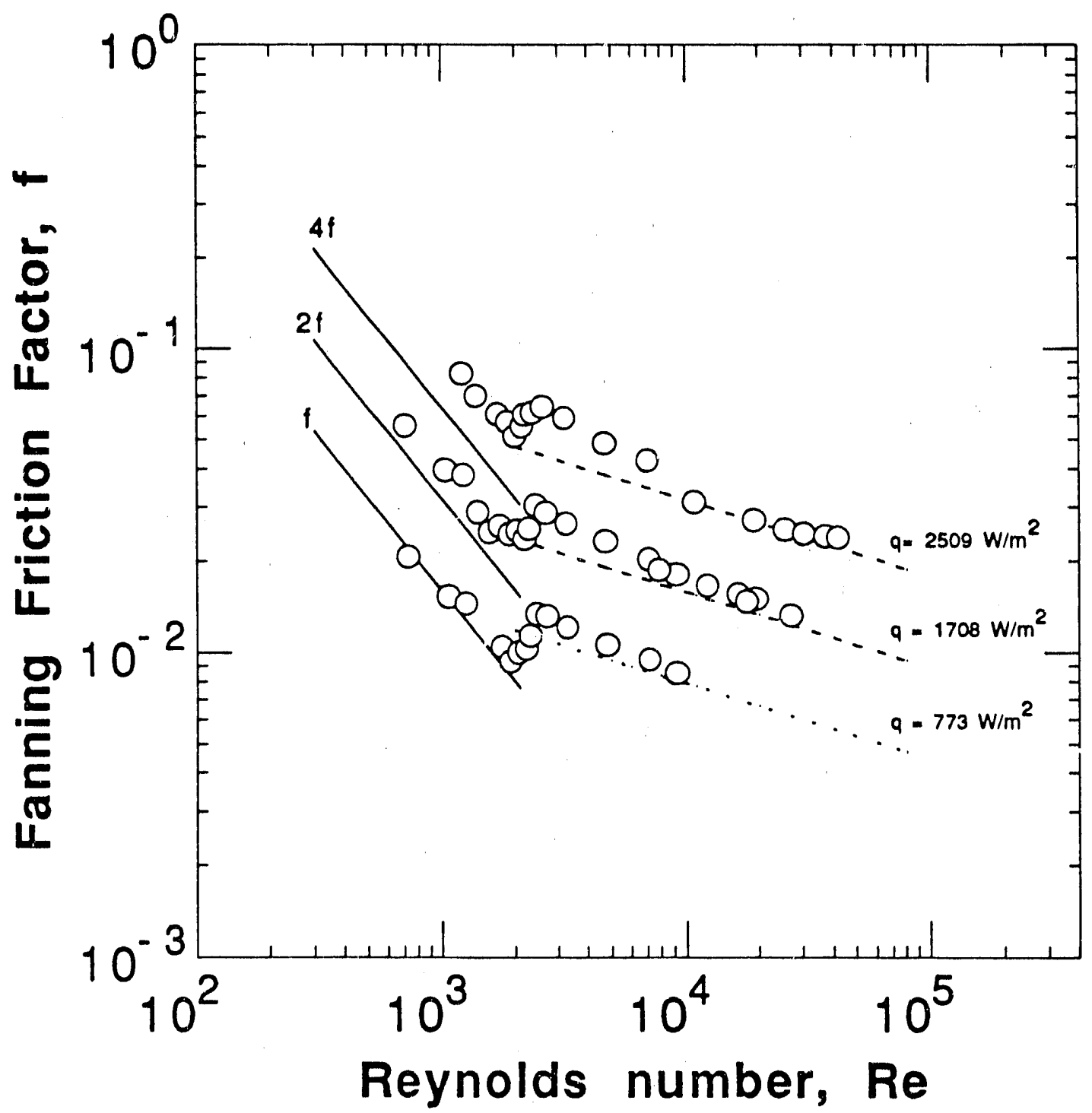

Figure 5. f vs. Re for three values of heat flux. 


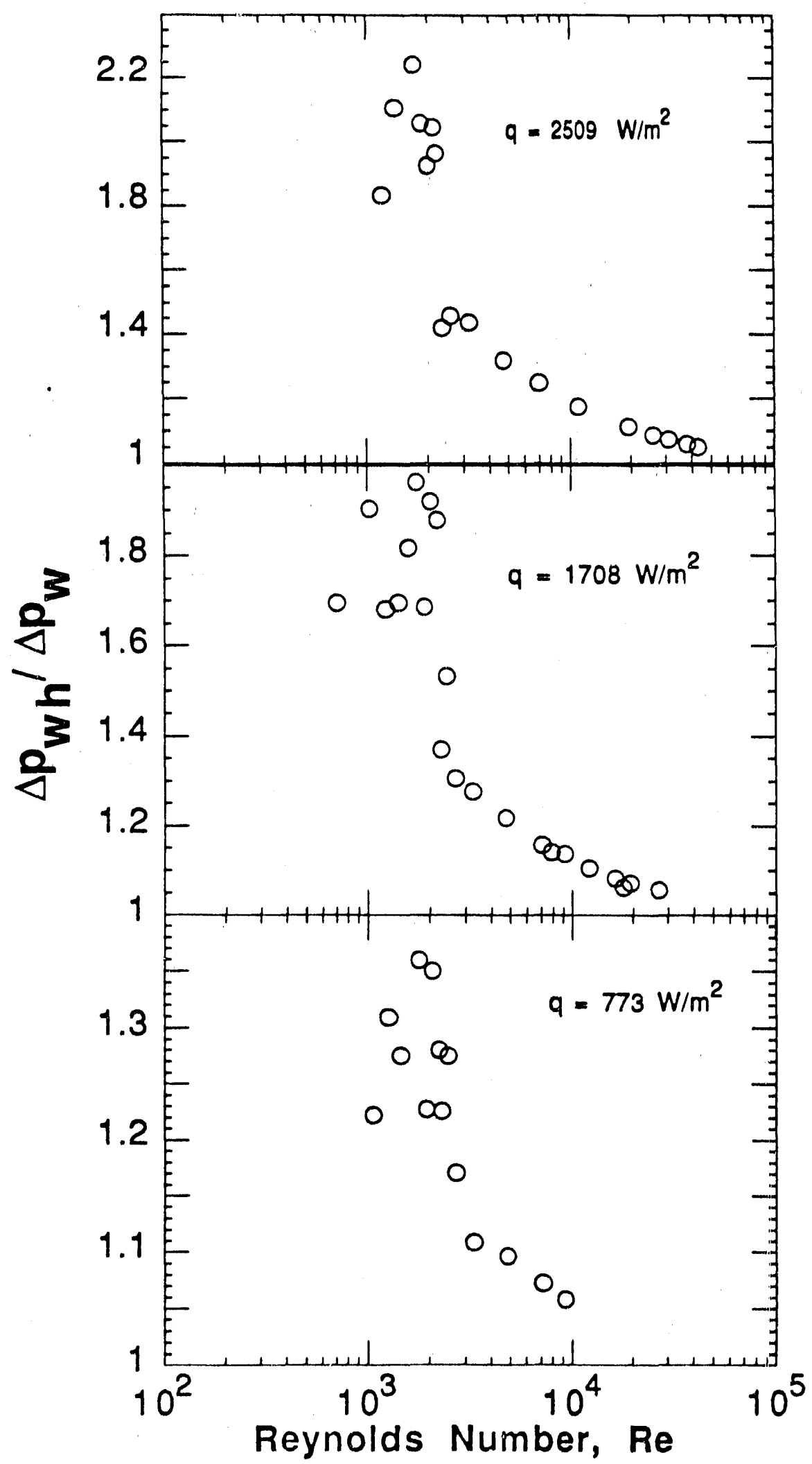

Figure 6. Pressure drop ratios for three values of heat flux 
an indication that the behavior of this profile may be used to detemine the onset of transition to turbulence. Another striking feature is the sharp decline in $\Delta p_{w h} / \Delta p_{w}$ values almost at the onset of fully turbulent flow. Also, it is apparent that $\Delta p_{w h} / \Delta p_{w}$ varies with heat flux for a given Reynolds number in laminar flow and in the transition zone.

It should be mentioned that the Reynolds number tested in the case of the constant surface temperature trials differed somewhat from those for which pressure drop data were obtained previously without heating; hence, the pressure drop ratios are not given for this situation. However, as documented in the next section for the Hitachi tube, the characteristic peaks in $\Delta p_{w h} / \Delta p_{w}$ profiles are also in evidence with the constant surface temperature tests.

\subsection{Enhanced Tube Heat Transfer and Friction Tests.}

On the basis of the results offiained with the smooth passage, the constant average surface temperature technique was adopted for tests with enhanced tubes; this in spite of the fact that this approach is very time consuming.

The results obtained with one of the Hitachi tubes are given, in Figures 7-10. The first two figures respectively are plots of $N u$ and $f$ versus $R e$, and in each figure the smooth tube data are included for the purpose of comparison. For the sake of clarity, not all smooth tube data are shown in Figure 7. The corresponding trend for $\Delta p_{w h} / \Delta p_{w}$ for the results of Figures 7 and 8 is illustrated in Figure 9. Although Figures 7-9 are for the situation where the average surface temperature was held fixed for all $R e$, limited tests were made with a constant heat flux $\left(q=1717 \mathrm{~W} / \mathrm{m}^{2}\right)$ for the $1000<R e<3500$ range and the $\Delta p_{w h} / \Delta p_{w}$ data for these trials are shown in Figure 10. The geometric characteristics of this tube are: helix angle $=28^{\circ}$; number of grooves $=10 ;$ relative height of roughness $\left(e / D_{\max }\right)=0.0216 ;$ where $e=$ roughness height $(0.30 \mathrm{~mm})$ and $D_{\max }=$ maximum internal diameter $(13.87 \mathrm{~mm})$.

It is evident from Figure 7 or 8 thai, with respect to heat transfer or friction, this tube behaves essentially as a smooth tube over almost the entire $R e$ range covered. The turbulent friction factors of Figure 8 for $R e=10000$ are moderately higher than the smooth tube values and this is also reflected in very slight increases in $N u$ for the same $R e$ range. Also, it is noted 


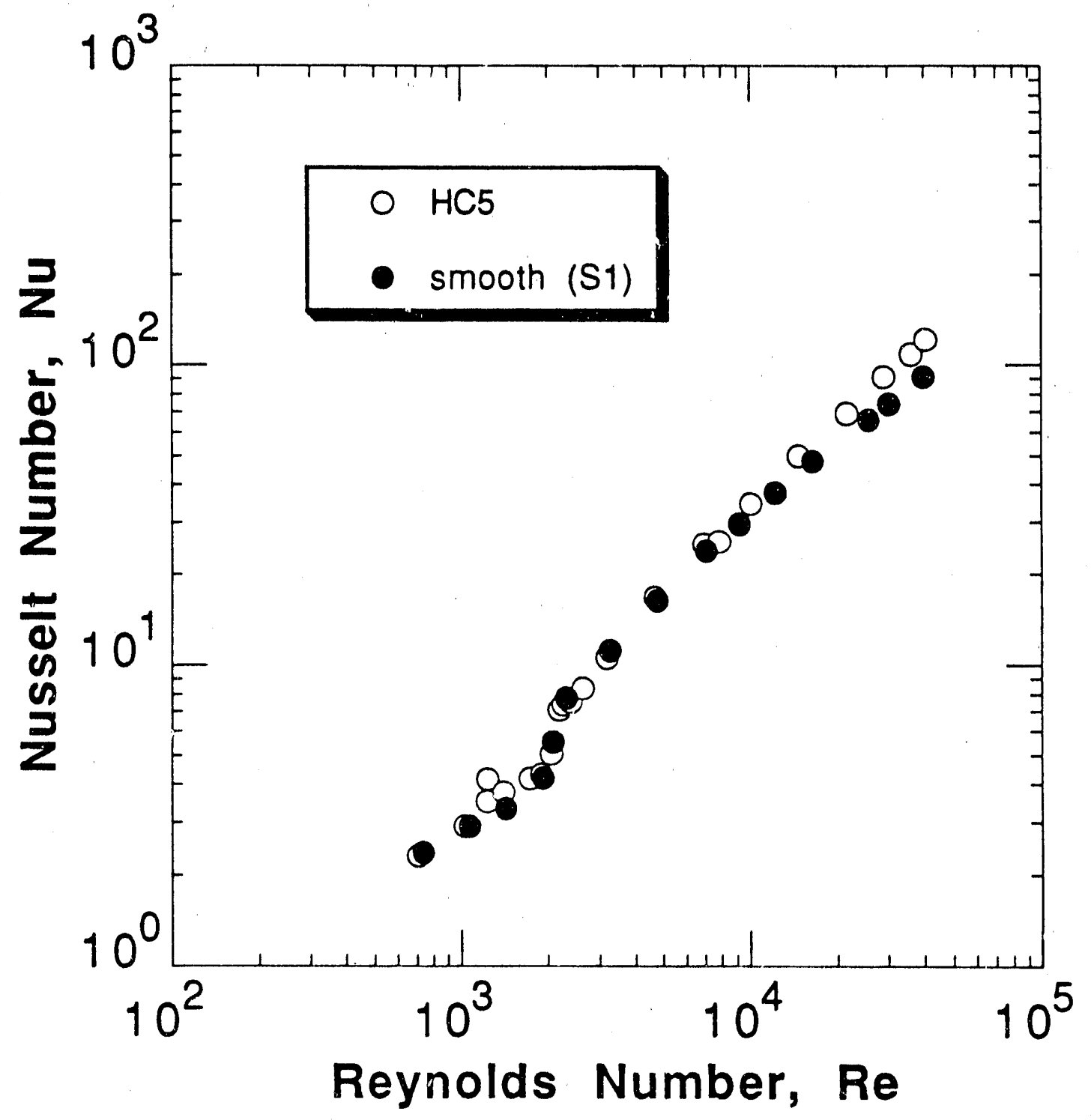

Figure 7. Comparison of smooth and Hitachi tube Nu data (fixed average surface temperature). 


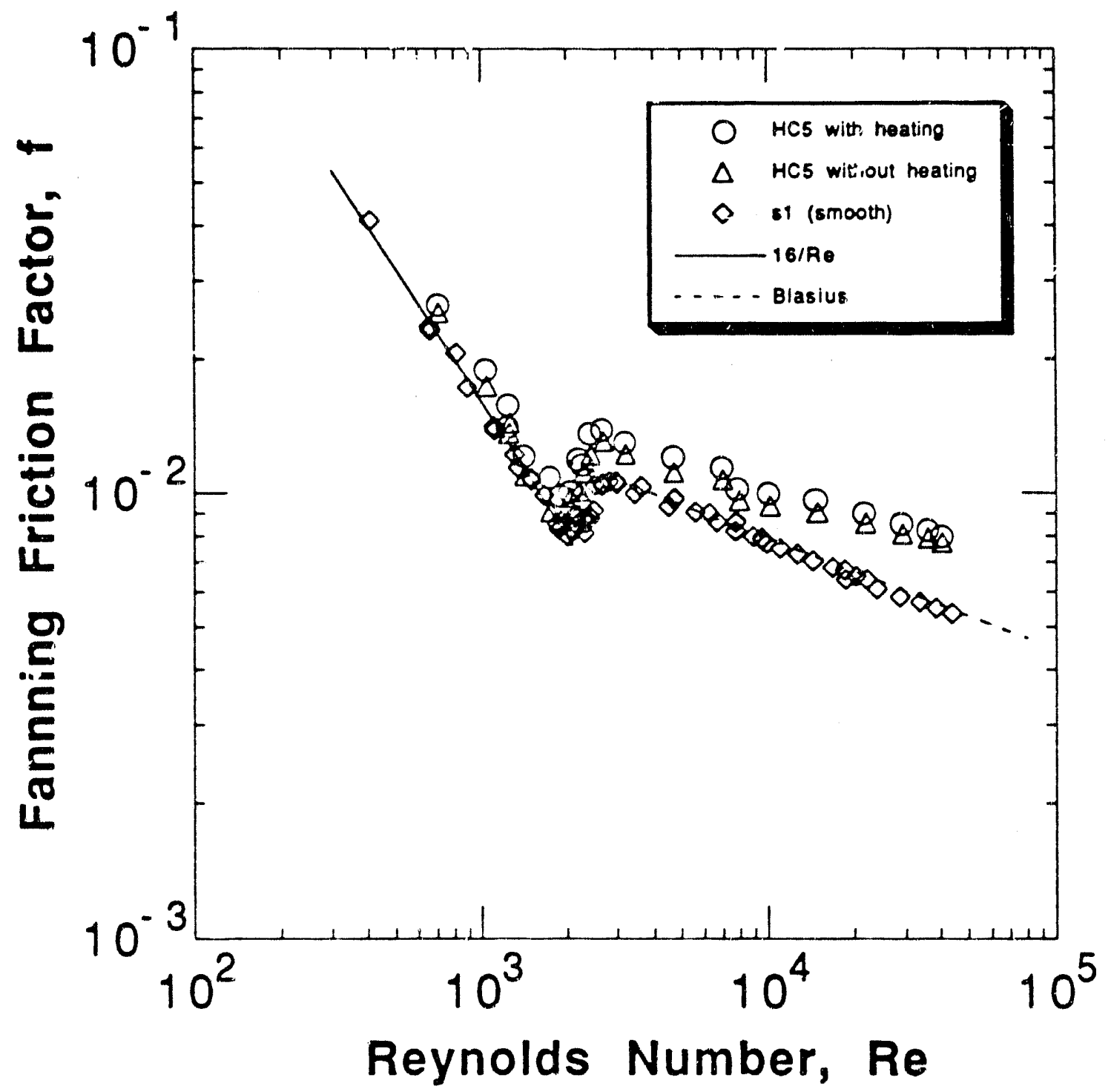

Figure 8. Comparison of smooth and Hitachi tube $f$ data (fixed aveiage surface temperature). 


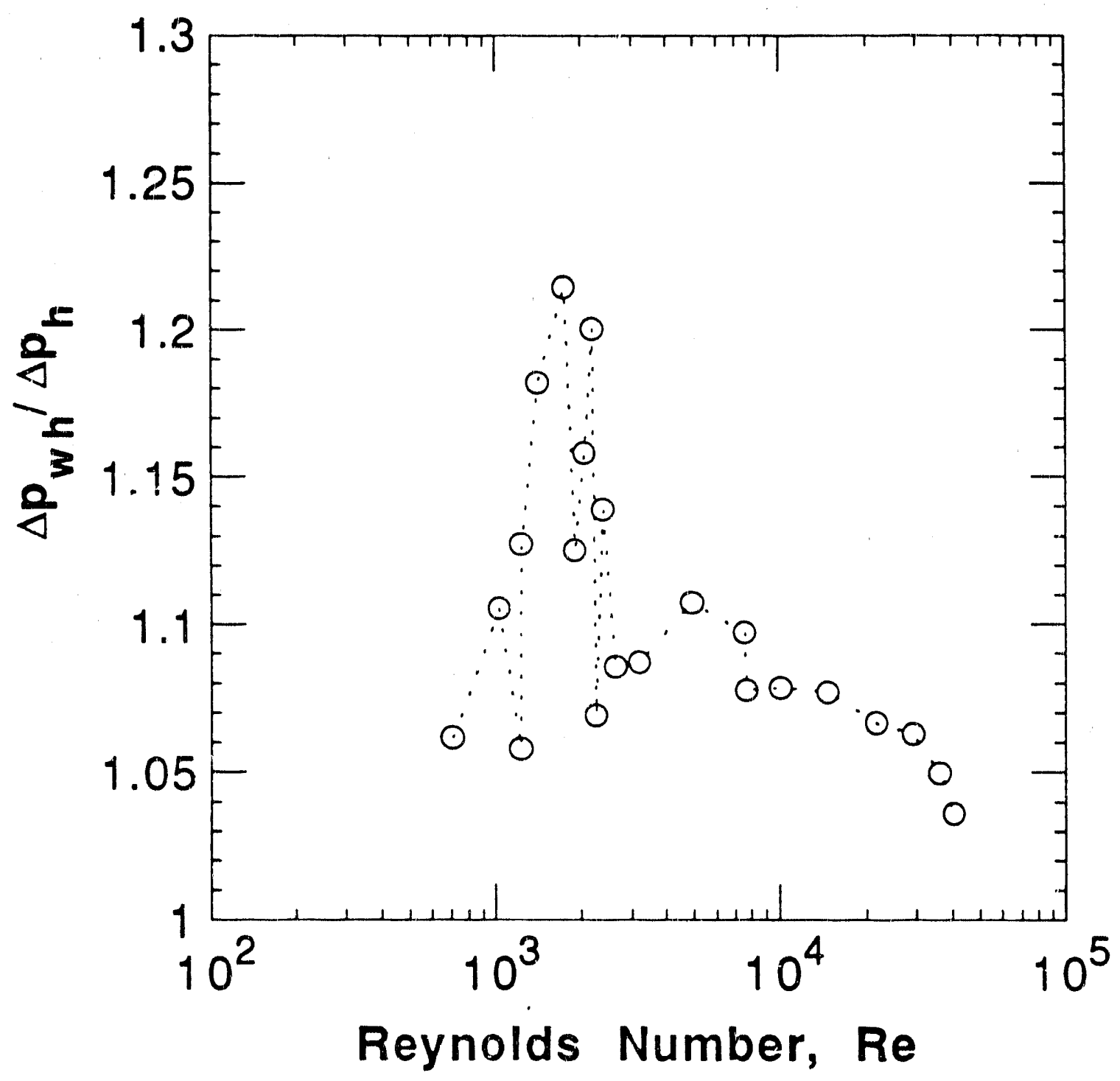

Figure 9. Pressure drop ratios with Hitachi tube for fixed average surface temperature. 


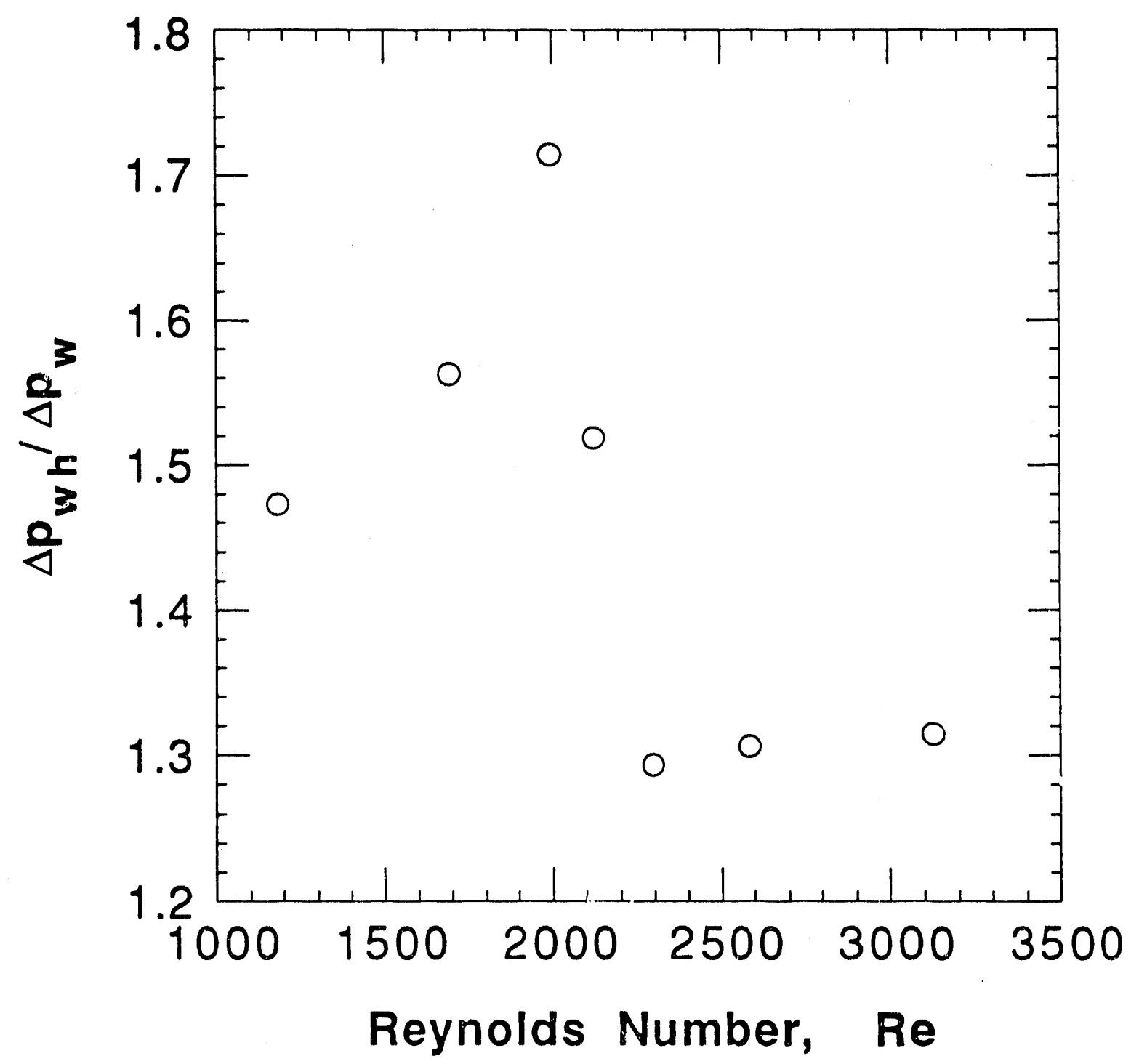

Figure 10. Pressure drop ratios with Hitachi tube for $q=1717 \mathrm{~W} / \mathrm{m}^{2}$. 
from Figure 8 that the enhanced tube critical Reynolds number at the onset of transition is only slightly lower than that of the smooth tube.

Another important observation relates to the sharp rise in $\Delta p_{w h} / \Delta p_{w}$ values within the transition region, a trend that is realized by maintaining either a constant average surface temperature (Figure 9) or a constant heat flux (Figure 10). Although the fact that the pressure drop must increase with heating for air was expected, the more pronounced effect of heat transfer on friction within the transition zone was unexpected. Suffice it to state that further studies and analyses are necessary to provide a better understanding of the phenomenon.

\section{FUTURE PLANS AND PROJECTIONS.}

1. We expect to complete testing of the remaining Hitachi tube and the Yampolsky aluminum tube by December 31, 1990; inclusive of all data reduction. This is to be followed by the preparation of three manuscripts dealing with the smooth tube, the Hitachi tubes, and with pressure drop and heat transfer with the Yampolsky tube.

2. Testing with the seven Wieland (German) tubes is scheduled for January and February, 1991.

3. The ten Yorkshire tubes (not thirteen as stated in the last progress report) were received in September 1990. At a cost of about $\$ 350$ per tube, fabrication of these test sections has not been made due to lack of funds. However, we are exploring in-house fabrication of the test sections, in which case, testing with these should be completed by $4 / 31 / 90$.

4. It should be emphasized that, to date, all tests were carried out with air as the working fluid. This will be the case for the projected tests outlined above. Experiments with liquids will begin after completion of the air studies.

\section{REFERENCES}

Kaupas, V. E., Poskas, P. S., and Vilemas, V. J., 1989, "Heat Transfer to a Transition-Range Gas Flow in a Pipe at High Heat Fluxes (2. Heat Transfer in Laminar to Turbulent. Flow 
Transition)," Heat Transfer-Soviet Research, Vol. 21, No. 3, pp. 340-351.

Koch, R., "Pressure Loss and Heat Transfer for Turbulent Flow," AEC-tr-3875 (1960).

Nunner, W., "Heat Transfer and Pressure Drop in Rough Tubes," AERE Lib/Trans 786 (1956).

Petukhov, B. S., and Popov, V. N., 1963, "Theoretical Calculation of Heat Exchange and Frictional Resistance in Turbulent Flow in Tubes of an Incompressible Fluid with Variable Physical Properties," High Temperature, Vol. 1, pp. 69-83.

Ravigururajan, T. S., and Bergles, A. E., "Study of Water-Side Enhancement for Ocean Thermal Conversion Heat Exchangers," HTL-44/ERI Project 1718, Iowa State University (1986).

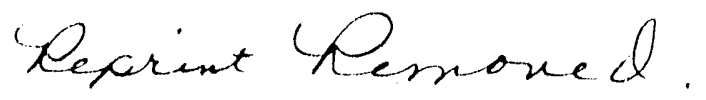




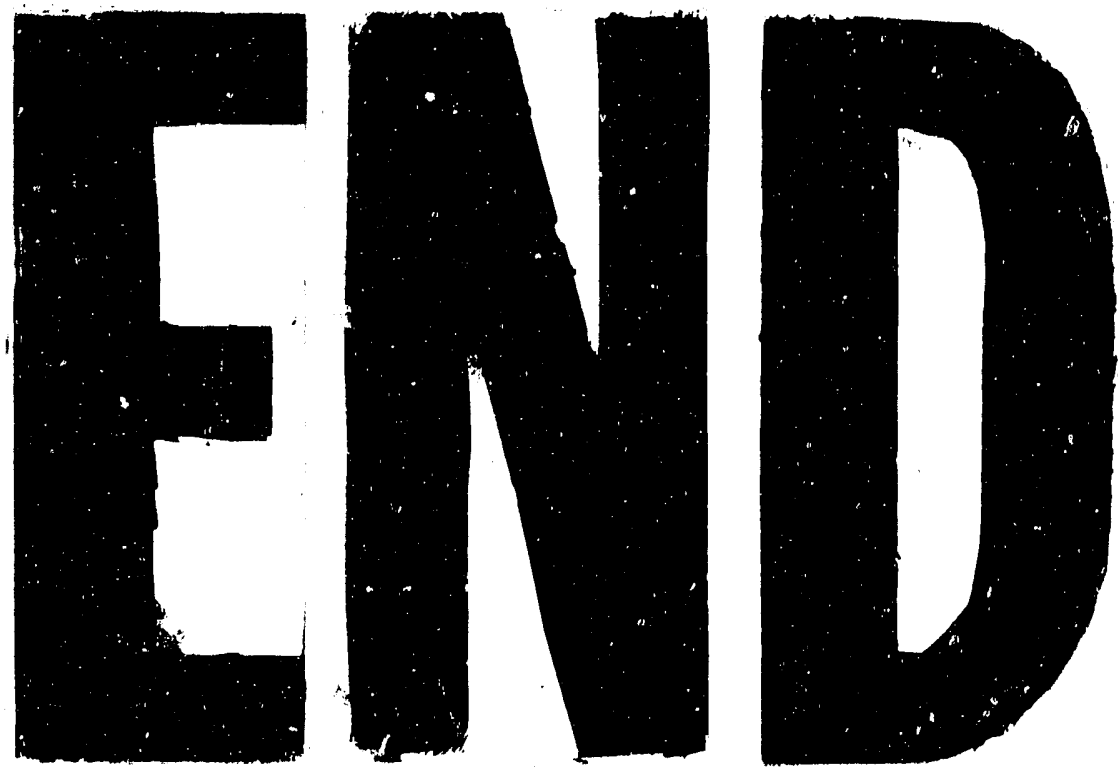

4
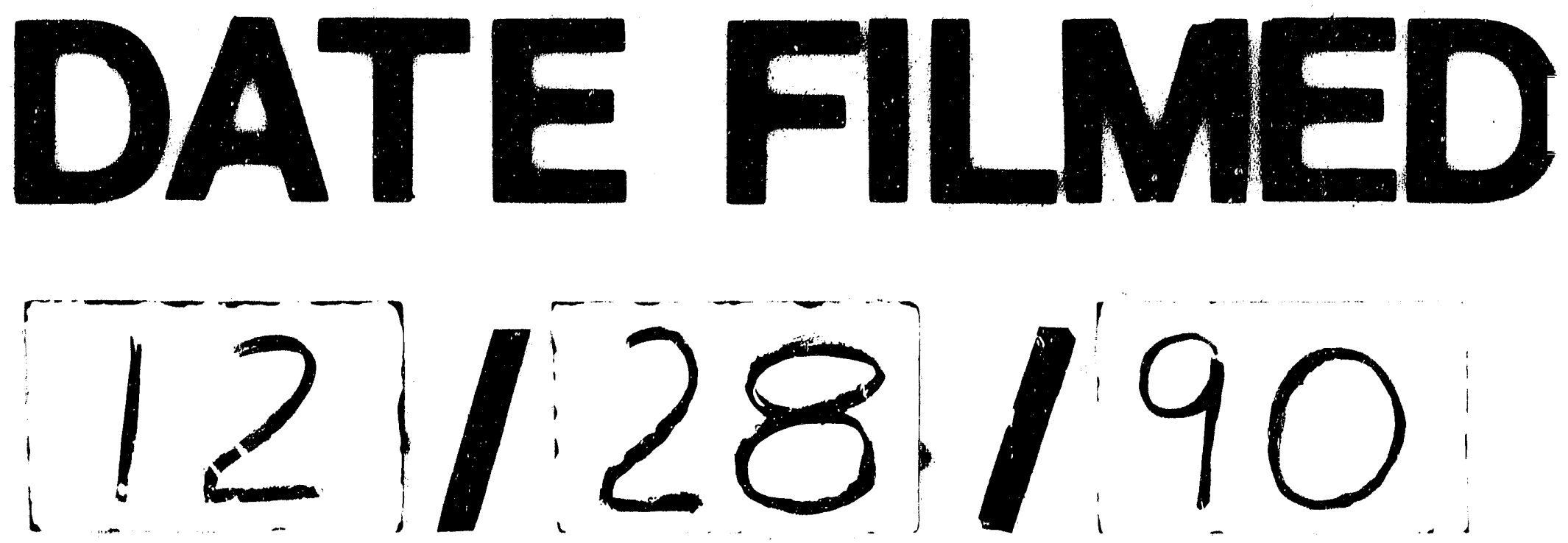
